\title{
Naturally aligned cell delivery platform to augment post-infarction neovasculature and ventricular remodeling
}

Hye Shin

Stanford Medicine

Akshara Thakore

Stanford Medicine

Yuko Tada

Stanford Medicine

Albert Pedroza

Stanford Medicine

Gentaro Ikeda

Stanford Medicine

Ian Chen

Stanford Medicine

Doreen Chan

Stanford Medicine

Kevin Jaatinen

Stanford Medicine

Masashi Kawamura

Stanford Medicine

Phillip Yang

Stanford Medicine

Joseph Wu

Stanford Medicine

Eric Appel

Stanford Medicine

Michael Fischbein

Stanford Medicine

Y Joseph Woo

Stanford Medicine

Yasuhiro Shudo ( $\square$ yasuhiroshudo@gmail.com )

Stanford Medicine 


\section{Research Article}

Keywords:

Posted Date: March 7th, 2022

DOI: https://doi.org/10.21203/rs.3.rs-1321790/v1

License: (c) (i) This work is licensed under a Creative Commons Attribution 4.0 International License. Read Full License 


\section{Abstract}

We demonstrated that joint delivery of human-derived endothelial progenitor cell (EPC) and smooth muscle cell (SMC) sheets mimics the native architecture of structurally mature blood vessels and contributes to limiting ventricular remodeling using a confluent SMC-EPC bi-level cell sheet engineered by cell-sheet technology and transplanted into an athymic rodent model of myocardial infarction. Enhanced vasculogenic potential was observed in vitro when EPCs were stimulated with SMC-conditioned culture medium, augmenting angiogenesis in vivo. Increased structurally mature vessel density, myocardial upregulation of biological adhesion, and vasculature developmental genes in the ischemic border zone myocardium showed interaction between cells and the extracellular matrix. Cell fate tracking experiments featuring xenogeneic transplantation showed transplanted EPCs and SMCs to have elements of the newly formed vasculature. Specialized magnetic resonance imaging of the cell-sheet-transplanted rodents suggested prolonged cell retention. The robust angiogenic effect of the transplanted cell sheets induced reverse ventricular remodeling of the ischemic heart. Bioinformatic analyses indicated that these cell sheets promote transcriptome-wide changes in the left ventricular response to acute ischemia, promote productive remodeling, and prevent pathological ventricular dilation. Thus, the human-derived, spatially arranged SMC-EPC bi-level cell sheet is a promising therapy for increasing myocardial viability and limiting adverse ventricular remodeling after myocardial infarction.

\section{Introduction}

The ischemic heart disease spectrum is the leading cause of death and morbidity in the USA [1]. An estimated 20 million people suffer from coronary artery disease, whereas 6 million have heart failure in the USA. More than one million patients a year have acute myocardial infarction (MI) with short-term mortality that still exceeds 7\%, despite maximal aggressive therapy [2]. Atop these numbers, the American Heart Association has forecasted that over the next two decades, there will be even further increases in the prevalence of coronary heart disease $(+17 \%)$ and heart failure $(+25 \%)$ [3]. Even mainstay therapies, such as percutaneous coronary intervention and coronary artery bypass graft, leave many patients incompletely revascularized. More importantly, microvascular malperfusion, unaddressed by current therapies [4], leads to cardiomyocyte dysfunction and injury, ventricular remodeling, and progressive functional deterioration. Therefore, there is a great need for effective therapy to restore microcirculation.

In our previous studies, we indicated that rodent-origin, bone marrow-derived, anatomically oriented, bilevel cell sheets made of isolated endothelial progenitor cells (EPCs) and trans-differentiated smooth muscle cells (SMCs) are a multi-lineage cellular therapy, obtained from a translationally practical source. Delivery of a tissue-engineered construct that maintains important interactions between EPCs and SMCs enhances mature neovascularization within the border zone myocardium, minimizes post-infarction adverse remodeling, strengthens ventricular function in a rodent model of ischemic cardiomyopathy, and is a highly optimal therapeutic cell delivery platform $[5,6]$. We have recently identified a modified method for SMC transdifferentiation from bone marrow-derived mesenchymal stem cells (MSCs) [7]. We are currently working on developing preclinical human-origin EPCs and SMCs from human bone marrow. 
In this study, we hypothesized that the joint delivery of human-derived EPCs and SMCs in a cell sheet would mimic the native architecture of a structurally mature blood vessel and contribute to cell engraftment and limit post-infarction ventricular remodeling. We aim to continue this line of work toward advancing potential translational therapeutics.

\section{Methods}

All methods were carried out in accordance with relevant guidelines and regulations. Our study was approved by the Institutional Review Board of Stanford University (IRB 32769). Informed consent was obtained from all subjects. The study is reported in accordance with ARRIVE guidelines.

\section{Animal care and biosafety}

Nude rats were obtained from Charles River, MA, USA. Food and water were provided ad libitum. All animal experiments were performed in concordance with the Guide for the Care and Use of Laboratory Animals (United States National Institutes of Health, 8th Edition, 2011). All animal procedures were approved by the Institutional Animal Care and Use Committee at Stanford University (Protocol 28921).

\section{EPC isolation and cell culture}

Blood outgrowth EPCs were isolated from healthy human donors' peripheral blood, as previously reported [49]. In summary, approximately $27 \mathrm{~mL}$ of blood was collected in a sterile manner and diluted with phosphate-buffered saline (PBS, > 1:1). Density-gradient centrifugation was conducted by layering the blood sample over a Ficoll-Paque solution and centrifuging for $20 \mathrm{~min}$ at 1,000 $\times g$ at RT. The buffy coat layer containing the mononuclear fraction of peripheral blood, including EPCs, was carefully harvested and washed with Hank's balanced salt solution (HBSS) by centrifuging for $10 \mathrm{~min}$ at $300 \times \mathrm{g}$. The supernatant was discarded and the pellet was resuspended in HBSS. After two washes, the isolated EPCs were resuspended in EGM-2 BulletKit (Cat. CC-3162; Lonza Inc., NJ, USA) and seeded on a 24-well plate that was previously coated with $0.2 \%$ gelatin for approximately $2 \mathrm{~h}$ at a density of $1.5 \times 10^{5}$ cells per well. The cells were incubated at $37^{\circ} \mathrm{C}$ in a $5 \% \mathrm{CO}_{2}$ atmosphere saturated with $\mathrm{H}_{2} \mathrm{O}$ until confluence. The cobblestone morphology of the cells was observed in the colonies that appeared on days 21 and 28 (Fig. 1A).

\section{Cell preparation of SMCs}

Human bone marrow-derived MSCs were purchased from Lonza Inc., NJ, USA and cultured in a 100-mm culture dish at a seeding density (SD) of $4-6 \times 10^{3} \mathrm{~cm}^{2}$ in minimum essential medium alpha (MEM a; Gibco, Thermo Fisher Scientific, MA, USA) supplemented with $20 \%$ fetal bovine serum (FBS; Hyclone, GE Healthcare Life Sciences, UT, USA), 5\% L-glutamine (Gibco, Life Technologies, CA, USA), and 1\% penicillin/streptomycin (P/S; Gibco, Life Technologies, CA, USA) at $37^{\circ} \mathrm{C}$ and $5 \% \mathrm{CO}_{2}$. Cells were cultured for 7-10 $d$, and the medium was exchanged every 3-4 $d$. The MSCs near confluence were then lifted and cultured on a 100-mm culture dish coated with fibronectin (BD Biosciences, CA, USA) at an SD of 4-6 $\times$ 
$10^{3} \mathrm{~cm}^{2}$ in Medium 231 supplemented with smooth muscle growth supplement (SMGS; Gibco, Life Technologies, $\mathrm{CA}, \mathrm{USA}), 10 \% \mathrm{FBS}$, and $1 \% \mathrm{P} / \mathrm{S}$ at $37^{\circ} \mathrm{C}$ and $5 \% \mathrm{CO}_{2}$ to induce SMC differentiation. SMC growth medium (Medium 231 with SMGS) was used as the nutrient medium and was exchanged every 2 d. MSCs grown under SMC growth conditions were passaged at least three times for expansion and induction toward SMC lineage differentiation before biological tests (Fig. 1A) [7]. Commercially available human aortic smooth muscle cells (AoSMC; Lonza Inc., NJ, USA) were cultured in the same medium condition at an SD of $3.5 \times 10^{3} \mathrm{~cm}^{2}$ for comparative purposes.

\section{Immunohistochemical assessment of the morphological characteristics of EPCs and SMCs}

Approximately 40,000-60,000 cells were cultured on four-well chamber slides (Nunc ${ }^{\text {TM }}$ Lab-Tek $^{\text {TM }}$ II Chamber Slide ${ }^{\text {TM }}$ System, Cat. 154526PK; Thermo Fisher Scientific, CA, USA) and incubated overnight at $37^{\circ} \mathrm{C}$ to allow them to attach to the bottom slides. After $24 \mathrm{~h}$, the cells were washed with PBS gently in the slides and fixed with 4\% PFA for 10 min at RT. Following fixation, the cells were washed with $3 \%$ bovine serum albumin (BSA) diluted in PBS and incubated in 0.5\% PBS-Tween for $15 \mathrm{~min}$ at RT. After washing with PBS, the cells were blocked with $10 \%$ FBS for an hour at RT. Following three washes, the cells were incubated with the appropriate primary antibodies overnight at $4^{\circ} \mathrm{C}$ and washed with anti-CD31 (1:200, Abcam, Cambridge, UK; Cat: ab24590), anti-CD34 (1:100, Invitrogen, CA, USA; Cat: PA5-32322), and antiHLA (1:200, Abcam, Cambridge, UK; Cat: ab52922) for EPCs, and with anti-SM22-a (1:100, Abcam, Cambridge, UK; Cat: ab14106), and anti-Caldesmon (1:100, Abcam, Cambridge, UK; Cat: ab212964) for SMCs. The cells were then stained with the appropriate secondary antibodies in the dark for $45 \mathrm{~min}$ at $37^{\circ} \mathrm{C}$ and washed again: (goat anti-mouse Alexa Fluor 488 secondary antibody (1:200, Abcam, Cambridge, UK; Cat: ab150113), goat anti-rabbit Alexa Fluor 488 secondary antibody (1:200, Abcam, Cambridge, UK; Cat: ab150077), donkey anti-goat Alexa Fluor 488 secondary antibody (1:200, Abcam, Cambridge, UK; Cat: ab150129), goat anti-rat Alexa Fluor 488 secondary antibody (1:200, Abcam, Cambridge, UK; Cat: ab150165), goat anti-mouse Alexa Fluor 594 secondary antibody (1:200, Abcam, Cambridge, UK; Cat: ab150116), goat anti-rabbit Alexa Fluor 594 secondary antibody (1:200, Abcam, Cambridge, UK; Cat: ab150080), donkey anti-goat Alexa Fluor 594 secondary antibody (1:200, Abcam, Cambridge, UK; Cat: ab150132), goat anti-mouse Alexa Fluor 647 secondary antibody (1:200, Abcam, Cambridge, UK; Cat: 150115), donkey anti-rabbit Alexa Fluor 647 secondary antibody (1:200, Abcam, Cambridge, UK; Cat: 150075), and donkey anti-goat Alexa Fluor 647 secondary antibody (1:200, Abcam, Cambridge, UK; Cat: 150131). Finally, the samples were incubated with 4',6-diamidino-2-phenylindole (DAPI) (1:100, NucBlue Fixed Cell ReadyProbes Reagent, Thermo Fisher Scientific, MA, USA; Cat: R37606) for nuclear staining in the dark for 3-5 min at RT. After washing, the samples were stored in PBS at $4^{\circ} \mathrm{C}$ for imaging.

\section{Flow cytometry to evaluate EPC and SMC phenotypes}

Flow cytometry was employed to identify the phenotypes of cultured EPCs and differentiated SMC lineages using EPC-and SMC-specific markers, respectively. We generated $10^{6} / \mathrm{mL}$ EPC and SMC single- 
cell suspensions and assessed these for cell numbers and viability using Trypan blue dye. The cells were then washed with PBS and incubated with the Zombie Aqua Fixable Viability Kit (1:20, BioLegend, CA, USA; Cat. 423101) in the dark for $30 \mathrm{~min}$ at RT to exclude the dead cell population. After incubation, the cells were washed twice with flow cytometry staining buffer and centrifuged for $5 \mathrm{~min}$ at $300 \times g$ twice. The EPCs were then incubated with the following three surface antibodies on ice for 30 min in the dark: APC-conjugated CD31 (1:100, eBioscience, CA, USA; Cat: 17-0319-42) and PE-Cy7-conjugated CD34 (1:100, eBioscience, CA, USA; Cat: 25-0349-42). For SMCs, the cells were first fixed with fixation medium (Reagent A of FIX \& PERM ${ }^{\text {TM }}$ Cell Permeabilization Kit; Thermo Fisher Scientific, MA, USA) for 15 min at RT. After two washes with staining buffer, the SMCs were incubated with permeabilization medium (Reagent B of FIX \& PERM ${ }^{\text {TM }}$ Cell Permeabilization Kit; Thermo Fisher Scientific, MA, USA) and three intracellular antibodies on ice for 30 min in the dark: PE-conjugated a-SMA (1:100, Abcam, Cambridge, UK; Cat: ab209435), APC-conjugated SM22-a (1:100, Abcam, Cambridge, UK; Cat: ab14106 (the primary antibody was conjugated using Lightning-Link APC labeling kit; Novus Biologicals LLC, CO, USA), and AF700conjugated caldesmon (1:100, Novus Biologicals LLC, CO, USA; Cat: NBP2-47819AF700). Thereafter, the EPCs and SMCs were washed twice, centrifuged for $5 \mathrm{~min}$ at $300 \times \mathrm{g}$, and stored in a fresh buffer until analysis. A portion of the cell suspension was used for compensation staining. The percentage of SMCs expressing each intracellular antigen was analyzed using a Becton Dickinson LSR II flow cytometer (BD Biosciences, CA, USA). EPCs expressing each surface antigen were analyzed using Novocyte Quanteon (Agilent, CA, USA). Data analysis was performed using FlowJo vX.

\section{Angiogenesis assay to assess the interaction between EPCs and SMCs}

To assess the synergistic effect of SMC cytokines and endothelial growth factors on the angiogenic potential of EPCs, an in-vitro Matrigel angiogenesis assay was performed. Growth factor-reduced Matrigel (Corning, NY, USA; Cat: 354263 ), thawed at $4^{\circ} \mathrm{C}$ overnight, was used to coat each well of a 15 -well $\mu$-Slide (Ibidi, Gräfelfing, Germany; Cat: 81507) and allowed to polymerize for $30 \mathrm{~min}$ at $37^{\circ} \mathrm{C}$ in $5 \% \mathrm{CO}_{2}$. Fifteen thousand cells were seeded in each well and cultured in one of the following experimental medium conditions: fresh EGM-2 medium or 48-h SMC-cultured EGM-2 medium. The well plate was incubated for $24 \mathrm{~h}$ at $37^{\circ} \mathrm{C}$ in $5 \% \mathrm{CO}_{2}$ and observed at $2,4,6$, and $8 \mathrm{~h}$ to monitor the progress of tube formation. The images were then analyzed using Angiogenesis Analyzer ImageJ plugin $(17,50)$.

\section{Creation of human-derived SMC and EPC bi-level cell sheets}

Cell sheets were created on and removed from a specialized dish, called Upcell dish (CellSeed, Tokyo, Japan), grafted covalently with a temperature-responsive polymer-poly (N-isopropyl acrylamide), which undergoes an enzyme-free transformation from hydrophobic to hydrophilic at lower temperatures (Fig. 2A). This temperature-sensitive dish allows the fabrication of three-dimensional tissue constructs from densely adherent cells, without an artificial scaffold or enzymatic digestion. The cell sheets created thus can be handled easily and have a unique ability to integrate within native tissue; they retain cell-cell 
junctions and the ECM deposited on the basal surface of the cell sheets. Human-origin transdifferentiated SMCs were plated on a 35-mm Upcell dish at a density of $1.5 \times 10^{5} / \mathrm{cm}^{2}$ and cultured in 231 medium for $24 \mathrm{~h}$ at $37^{\circ} \mathrm{C}$ in $5 \% \mathrm{CO}_{2}$. After $24 \mathrm{~h}$ of incubation, EPCs of human origin were carefully seeded at $1.5 \mathrm{x}$ $10^{5} / \mathrm{cm}^{2}$ on top of the confluent SMC layer on the same dish and cultured in EGM-2 medium for an additional $24 \mathrm{~h}$. After incubation, the dish containing a bilayer of two different confluent cell types was transferred at RT to lift the cells as an intact SMC-EPC bi-level cell sheet.

\section{Using SEM to visualize topological variations of SMC-EPC bi-level cell sheets}

We hypothesized that the bilayer of SMCs and EPCs would remain densely adhered to one another as an intact cell sheet, despite lacking an artificial scaffold. We used SEM to observe their morphologies and interactions with one another closely (Fig. 2D-E). The bi-level cell sheet lifted from the UpCell dish was fixed with $4 \%$ paraformaldehyde and $2 \%$ glutaraldehyde in $0.1 \mathrm{~mol} / \mathrm{L}$ sodium cacodylate buffer $(\mathrm{pH} \mathrm{7.2)}$ for $24 \mathrm{~h}$ at $4^{\circ} \mathrm{C}$, rinsed in the same buffer, and post-fixed with $1 \%$ aqueous osmium tetroxide for an hour. After dehydration in an ascending ethanol series (50\%, 70\%, 90\%, and 100\% [2x] for 10 min each), the sample was pressed onto carbon paint and sputter-coated with $\mathrm{Au}: \mathrm{Pd}(60: 40)$ before imaging. The SEM images were acquired using an FEI Magellan 400 XHR microscope with a beam voltage of $8 \mathrm{kV}$ and a dwell time of $30 \mu \mathrm{s}$.

\section{Athymic rat MI model and cell-sheet transplantation}

A proximal region of the left anterior descending coronary artery of female athymic rats (Fig. 4A) (F344/NJcl-rnu/rnu, 8-week-old, female, 150-180 g; Charles River, MA, USA) was permanently occluded using a left thoracotomy approach. We utilized an established ischemic cardiomyopathy model with a resultant Ml encompassing 40\% of the left ventricle. Each operated rat was allocated to one of two groups: 1) transplantation of SMC-EPC bi-level cell sheet (cell sheet group, $n=10$ ) or 2 ) no treatment (untreated control group, $n=14$ ). These two groups were compared to 3 ) rats that received a sham operation (a positive control, $n=10$ ) (Fig. 4B). In the cell sheet group, the bi-level cell sheet, which consisted of $1.5 \times 10^{6} \mathrm{EPCs}$ and $1.5 \times 10^{6} \mathrm{SMCs}$, was placed on the epicardium covering the ischemic area. The animals were then kept for 8 weeks and then euthanized by intravenous injection of $2 \mathrm{mEq} / \mathrm{kg}$ potassium chloride under terminal anesthesia. Their hearts were collected for histological analysis (Fig. 3C).

\section{Evaluating ventricular remodeling and cardiac function, mass, and myocardial viability}

Cardiac MRI was performed at 8 weeks after the treatment procedure using a Signa 3T EXCITE scanner (GE Healthcare, WI, USA) and a phased array 4 channel surface coil (Rapid MR international) [5, 51]. During the entire scan, the rats were anesthetized using 1.0-3.0\% isoflurane. ECG gating and respiratory and body temperatures were monitored using PC-SAM (SA Instruments Inc., NY, USA). The LV function was evaluated on short-axis serial slices obtained by an ECG-triggered fast spoiled gradient-recalled 
(FSPGR) sequence. Nonviable and viable myocardium was discriminated against using MEMRI, which was performed using an ECG-triggered IR-FSPGR sequence approximately $60 \mathrm{~min}$ after the subjects were given an intraperitoneal injection of $10 \mathrm{~mL} / \mathrm{kg}$ of EVP103 (Eagle Vision Pharmaceutical) [52, 53]. The LV contours were traced manually to calculate LVEDV, LVESV, and LV ejection fraction (LVEF). A manganesebased contrast agent (EVP 103) was taken up by L-type calcium channels to confer T1-shortening and positive signals on the viable myocardium. Myocardial viability was calculated by tracing MEMRI enhancement. MEMRI viable myocardial volume $(\%)=($ MEMRI enhancement volume $\times 100) /$ total LV mass volume.

\section{USPIO-enhanced MRI assesses engraftment of transplanted donor cells}

We hypothesized that a significant portion of the transplanted SMC-EPC cell sheet would be engrafted onto the native tissue. To test this hypothesis, SMCs and EPCs were first magnetically labeled before cellsheet creation and transplantation. An adherent monolayer of differentiated SMCs or EPCs was cultured and lifted when it reached $80-90 \%$ confluence and was resuspended in serum-free Dulbecco's modified Eagle's media at a density of $4 \times 10^{6}$ cells $/ \mathrm{mL}$ for labeling. Each cell type suspension was mixed with protamine $\left(60 \mu \mathrm{g} \mathrm{mL}^{-1}\right)$ and ferumoxytol $\left(50 \mu \mathrm{g} \mathrm{mL}^{-1}\right)$ from stock drugs and incubated for 2-4 $\mathrm{h}$ at RT. After the iron labeling, an equal amount of complete medium containing 10-20\% FBS was added to the cells and incubated overnight at RT. The iron-labeled cells were then washed with PBS and used to create cell sheets using the method described above.

Iron labeling was confirmed using USPIO with FDA-approved ferumoxytol injection (Feraheme; 1,000 $\mathrm{mg} / \mathrm{mL}$; AMAG Pharmaceuticals, Inc., MA, USA). Cardiac MRI was performed using a Signa 3T EXCITE scanner (GE Healthcare, IL, USA) and a phased array 4 channel surface coil (Rapid MR International, LLC, $\mathrm{OH}, \mathrm{USA}$ ). During the entire scan, the rats were anesthetized using $1.0-3.0 \%$ isoflurane. ECG gating and respiratory and body temperatures were monitored using PC-SAM (SA Instruments Inc., Maharashtra, India). The iron-labeled cells in the transplanted cell sheet were detected as dephasing signal loss on gradient-echo (GRE) sequence on days $1,7,14,28,42$, and 56 post-transplantation. The GRE images were obtained on LV short-axis planes to cover the whole heart (flip angle $=35^{\circ}, T R=1 R R, T E=9 \mathrm{~ms}$, trigger delay $=12 \mathrm{~ms}, \mathrm{NEX}=6$, matrix $=256 \times 192, \mathrm{FOV}=4 \mathrm{~cm}$, thickness $=1.5 \mathrm{~mm}, \mathrm{BW}=122 \mathrm{~Hz} /$ pixel). The USPIO-labeled areas in the samples were measured and corrected by the USPIO density values of interest at the mid-LV level (clearly depicting the base of the papillary muscles) $[54,55]$.

\section{Morphological alterations following SMC-EPC cell sheet transplantation}

Eight weeks after the treatment procedure, hearts were arrested with potassium chloride and explanted to assess infarct size and tissue biocompatibility. The hearts flushed with PBS were injected retrogradely with Tissue Tek optimum cutting temperature (OCT) compound (Sakura Finetek Inc., CA, USA), frozen in it, and stored at $-80^{\circ} \mathrm{C}$. The frozen tissues were cross-sectioned along with the ventricle short-axis plan with $10 \mu \mathrm{m}$ thickness using a Leica CM3050S cryostat (Wetzlar, Germany) and stained with various 
histochemical stains. Digital photographs were taken with a NanoZoomer 2.0-RS (Hamamatsu, Japan) and Keyence BZ-X800 (Osaka, Japan) and were analyzed using the Image $\mathrm{J}$ software. The tissue sections for each of the three groups were stained with hematoxylin and eosin to evaluate morphological changes according to the manufacturer's instructions (Thermo Fisher Scientific; Cat: 9990001).

Periodic acid Schiff (PAS) staining was performed to assess hypertrophic response in the myocardium following each treatment, using the PAS stain kit (Cat No. ab150680; Abcam, Cambridge, UK). The tissue sections were first equilibrated for $5 \mathrm{~min}$ at RT before staining. The tissues were then incubated in PAS solution for $10 \mathrm{~min}$ at RT and washed with distilled water. The rinsed samples were incubated in Schiff's solution for $25 \mathrm{~min}$ and washed again. Following hematoxylin nuclear staining for 3 min and washing, the samples were dehydrated with $100 \%$ ethanol, mounted, and stored at RT for imaging.

\section{RNA sequencing to evaluate comprehensive transcriptomic characteristics}

Heart tissue was collected 7 days after surgery from sham, left anterior descending artery infarct, and infarct + cell sheet samples and dissected to separate the left ventricular into three zones encompassing the infarct, border zone, and unaffected (remote) tissues. The samples were snap-frozen in liquid nitrogen immediately after collection. Subsequently, the tissue samples were pulverized on dry ice and RNA was extracted using an RNeasy extraction kit (Qiagen, Germantown, MD). RNA sample integrity was ensured using a bioanalyzer. mRNA libraries were then generated using poly-A enrichment, and all the samples were sequenced simultaneously using a NovaSeq 6000 device using paired-end 150-bp reads. Raw sequencing BCL files were then demultiplexed into individual FASTQ files corresponding to each sample; these files were used as input into STARAligner v.2.5.4 to simultaneously trim sequencing reads and align to the mRatBN7.2 genome assembly. The resulting aligned reads were then mapped to Rattus norvegicus Annotation Release 108, and the individual sample count matrix files were generated. Downstream RNA sequencing analysis was performed using the DESeq2 package in R. All samples were merged into a single expression matrix data frame and normalized by sequencing depth before differential expression analysis.

\section{Immunohistochemical assessment of mature vessel formation}

After 8 weeks post-MI, whole rat hearts were dissected and embedded in OCT for histological assessment. Heart cryosections were stained with anti-von Willebrand factor (vWF) (1:100, Abcam, Cambridge, UK; Cat: ab11713) and anti-a-SMA (1:100, Abcam, Cambridge, UK; Cat: ab21027) to evaluate mature vessel density. The mature vessel density was calculated as the number of positively stained vessels per heart in five randomly selected fields within the peri-infarct border zone. Cell nuclei were counterstained with DAPI. Images were acquired with a fluorescence microscope (Leica, Wetzlar, Germany), and ImageJ was used for quantitative morphometric analyses.

Cell fate tracking to identify transplanted donor cells 
We designed cell sheets in specific ways to track their fate on the recipient's heart after transplantation. First, we created cell sheets with EPCs from a human female donor and SMCs from a human male donor and transplanted them onto a female athymic rat heart. The animals were sacrificed at 0-day and 8-week postoperative time points, and their hearts were sectioned as described above. The transplanted EPCs were tracked immunohistochemically with anti-HLA (1:100, Abcam, Cambridge, UK; Cat: ab52922) and anti-VEGFR2 (1:100, Abcam, Cambridge, UK; Cat: ab9530), whereas SMCs were tracked using antiSOX1(1:100, EMD Millipore, MA, USA; Cat: 07-1673) and anti-a-SMA (1:100, Abcam, Cambridge, UK; Cat: ab21027). Cell nuclei were counterstained with DAPI.

To corroborate the fate of the transplanted bi-level cell sheets on the recipient's myocardium, we labeled the cell sheets with iron as described above before transplantation. The iron-labeled cell sheets were transplanted onto athymic rat hearts following $\mathrm{MI}$, and the hearts were collected 8-week postoperatively.

Tissue sections were stained with the Prussian blue stain kit (Cat No. ab150674; Abcam, Cambridge, UK) to detect ferric iron in the tissues. The tissue sections were first equilibrated for $10 \mathrm{~min}$ at RT, followed by hydration in distilled water. The samples were then incubated in a working solution of hydrochloric acid with potassium ferrocyanide (1:1) for $5 \mathrm{~min}$ at RT. After incubation, the samples were rinsed with water, followed by nuclear staining with DAPI for 5 min. After rinsing, the samples were dehydrated in $95 \%$ ethanol and then absolute ethanol, and then mounted for imaging.

\section{Statistical analysis}

Continuous variables are expressed as the mean and standard error. The significance of differences was determined using Student's t-test for paired data. For comparisons among 3 groups, we used one-way analysis of variance, followed by 2-tailed multiple t-tests with Bonferroni's correction. Statistical significance was set at $p<0.05$. All calculations were performed using JMP 9.0 (SAS Institute Inc., NC, USA).

\section{Results}

\section{Characterization of EPCs and transdifferentiated SMC lineage}

The protocol used to manufacture the SMC-EPC bi-level cell sheets is illustrated in Fig. 1A. To characterize the isolated and transdifferentiated cells, immunocytochemistry for CD31, CD34, smooth muscle protein 22-alpha (SM22-a), and caldesmon was performed. Proportions of proteins indicative of EPC and SMC phenotypes were examined using flow cytometry analysis. Immunocytochemistry revealed CD31 and CD34 on the cultured EPCs (Fig. 1B). EPCs cultured for passages 6-7 after isolation were positive for CD31 $(99.9 \% \pm 0.03 \%)$ and CD34 $(81.1 \% \pm 8.2 \%)$ on their surface (Fig. 1C). MSCs were transdifferentiated into the SMC lineage when cultured in SMC growth medium on fibronectin-coated dishes. Immunocytochemistry demonstrated SM22-a and caldesmon in the cells (Fig. 1D). The obtained cells were highly positive for alpha-smooth muscle actin (a-SMA; $100.0 \% \pm 0.0 \%$ ), SM22-a $(99.9 \% \pm 0.1 \%$ ), 
and caldesmon $(89.5 \% \pm 2.7 \%)$ (Fig. 1E). Our protocol yielded human-derived EPCs and SMC lineages with high purity, which is consistent with previous reports [5-7] and is a promising cell source for translatable clinical applications.

\section{Enhanced EPC vasculogenic potential using SMC- conditioned culture medium}

The in-vitro analysis of vasculogenic potential performed using the tube formation assay showed significantly greater vessel formation, length, and branching in EPCs treated with SMC-conditioned endothelial cell growth medium-2 (EGM-2) than in EPCs treated with fresh EGM-2 ( $n=24$ in each group). For the observation period of 2-8 $\mathrm{h}$, there was a profound increase in total tubing in both groups (Fig. 2). Priming of EPCs with SMC-conditioned EGM-2 medium seems to significantly enhance the vasculogenic potential of EPCs. This in-vitro assay demonstrated the significant direct SMC-mediated vasculogenic potential of EPCs. These findings help explain the profound increase in vasculogenesis that was observed in vivo.

\section{Creation and characterization of SMC-EPC bi-level cell sheets}

The schema used to manufacture the SMC-EPC bi-level cell sheets is illustrated in Fig. 3A. Cell sheets were created on and removed from a specialized dish that was grafted covalently with a temperatureresponsive polymer poly ( $\mathrm{N}$-isopropyl acrylamide), which undergoes an enzyme-free transformation from hydrophobic to hydrophilic by the mere lowering of temperature. We created a circular-shaped, scaffoldfree SMC-EPC bi-level cell sheet in temperature-responsive culture dishes, which allowed for spontaneous detachment of the cell sheet from the culture surface after 20-30 min of incubation at room temperature (RT; Fig. 3B). We confirmed that the cell sheet was bi-level by immunohistochemistry (Fig. 3C). Scanning electron microscopy (SEM) revealed the presence of densely adherent cells without an artificial scaffold in the cell sheet. Moreover, morphological differences were noted between individual cells, different cell types, and the upper and lower surfaces of the cell sheets. The examination of the surface (EPC layer) of the SMC-EPC bi-level cell sheet suggested that the EPCs form a smooth confluent layer with cell borders in close contact with each other, thereby forming a thin film-like layer on top of the SMCs (Fig. 3D), whereas the examination of the bottom (SMC layer) of SMC-EPC bi-level cell sheet indicated that that SMC morphology varies regionally from spherical to flattened (Fig. 3E). This suggested that SMCs differentiated into elongated and spindle-shaped dense sheet-like constructs with cellular extensions to form a densely adherent layer. The interface between the two layers of the SMC-EPC bi-level cell sheet (SMC-EPC border zone) showed the development of a cross-linked structure (Fig. 3F).

\section{SMC-EPC bi-level cell sheets improved cardiac function, viability, and remodeling}


The effects of bi-level cell sheet transplantation on cardiac function were assessed in an athymic rat model of ischemic cardiomyopathy using cardiac magnetic resonance imaging (MRI) and manganeseenhanced MRI (MEMRI) (Fig. 4). Representative cardiac MRI at end-systolic and end-diastolic phases and MEMRI images are shown in Fig. 5. Compared to that in sham surgery, permanent ligation of the left anterior descending artery in untreated animals significantly decreased left ventricular (LV) ejection fraction with concomitant increases in LV end-systolic and end-diastolic volume 8 weeks after infarction, which are all characteristics of chronic ischemic heart failure. However, SMC-EPC bi-level cell sheet transplantation attenuated myocardial dysfunction, as evidenced by an increase in LV ejection fraction (untreated vs. cell sheet vs. sham, $37 \% \pm 2 \%$ vs. $41 \% \pm 2 \%$ vs. $69 \pm 2 \%$, respectively, $p=0.0001$ ), and induced significant reverse LV remodeling, as evidenced by decreases in LV dimensions [LV end-diastolic volume (LVEDV) in untreated vs. cell sheet vs. sham, $627 \pm 25 \mu \mathrm{L}$ vs. $447 \pm 30 \mu \mathrm{L}$ vs. $271 \pm 37 \mu \mathrm{L}$, respectively, $p=0.0001$; LV end-systolic volume (LVESV) in untreated vs. cell sheet vs. sham, $398 \pm 20 \mu \mathrm{L}$ vs. $265 \pm 24 \mu \mathrm{L}$ vs. $83 \pm 24 \mu \mathrm{L}$, respectively, $p=0.0001$ ] and LV mass (untreated vs. cell sheet vs. sham, $385 \pm 17 \mathrm{mg}$ vs. $364 \pm 20 \mathrm{mg}$ vs. $281 \pm 20 \mathrm{mg}$, respectively, $p=0.01$ ). Myocardial viability, as calculated by tracing MEMRI enhancement, demonstrated the recovery of the viable area following SMC-EPC bi-level cell sheet transplantation (untreated vs. cell sheet vs. sham, $71 \% \pm 2 \%$ vs. $76 \% \pm 2 \%$ vs. $100 \%$, respectively, $p=0.0001)$.

\section{Longitudinal changes in cell engraftment following SMC- EPC cell sheet transplantation}

Cell engraftment ratio was quantitatively calculated using ultrasmall superparamagnetic iron oxide (USPIO)-enhanced MRI images to assess the longitudinal change following SMC-EPC bi-level cell sheet transplantation (Fig. 5C). After $7 \mathrm{~d}$ of cell-sheet transplantation, the cell engraftment ratio was maintained as high as $92.4 \%$ of the baseline at $0 \mathrm{~d}$. After $14 \mathrm{~d}$, regression of cell engraftment occurred and the ratio decreased to $72.5 \%$ of the baseline at $0 \mathrm{~d}$. From 14 to $42 \mathrm{~d}$, this ratio was maintained at approximately $70 \%$ of the baseline at $0 \mathrm{~d}$. Eventually, the cell engraftment ratio at $56 \mathrm{~d}$ was still as high as $56.3 \%$ of the baseline at $0 \mathrm{~d}$, indicating that more than half of the iron-labeled cells could be detected at 8 weeks after transplantation (Fig. 5D).

\section{SMC-EPC cell sheet induced biological adhesion and vascular development pathways}

To comprehensively evaluate the effect of SMC-EPC bi-level cell sheet implantation on native tissue biological processes following $\mathrm{Ml}$, we processed whole rat heart tissue samples for bulk RNA sequencing 1 week after implantation. The samples from rats treated with cell sheets were compared with the corresponding samples from the infarction-only group and sham surgery controls $(n=5-6$ animals per group). To provide spatial context to the effect of cell sheet implantation, separate samples encompassing the anterior LV (infarct zone), lateral wall (border zone), and ventricular septum (remote) were used from each animal (Fig. 6A). Principal component analysis of the individual samples showed variable signatures in the anterior LV and border zone regions between the cell sheet-implanted group and 
the MI only group, suggesting substantial transcriptomic differences between these groups, whereas the sham group clustered within a tight PC spectrum, indicating minimal gene expression variation due to anatomic segments (Fig. 6B). To identify changes due to cell sheet implantation that may contribute to improvement in post-infarction myocardial function and ventricular remodeling, we directly compared the infarct and border zones of the cell between the sheet-treated group and the infarct-only group. This analysis identified 3,160 differentially expressed genes (DEGs), including 1,625 enriched in cell sheettreated hearts and 1,535 enriched in infarct-only samples. We then performed gene set enrichment analysis by ranking the DEGs in descending order of fold change and by analyzing this rank list to identify enriched biological processes in annotated gene ontology (GO) $[8,9]$.

We identified 114 significantly enriched processes in the cell sheet treated group, which included pathways related to embryogenic morphogenesis, biological adhesion, and vasculature development (Fig. 6C). The infarct-only group showed enrichment for pathways related to mitochondrial energetics, oxidative phosphorylation, and protein translation (Fig. 6D, 6E). Because we hypothesized that cell-ECM interaction and angiogenesis play critical roles in post-infarction cardiac performance, we further analyzed biological adhesion and vasculature development pathways for genes of interest in terms of spatial expression. For the adhesion pathway, we found increased expression of critical ECM components, including collagen VI isoforms and collagen subtypes associated with cardiac development and response to injury in the cell sheet-treated group (Col12a1 and Col1a 1) (Fig. 6F) [10]. The expression of each of these genes was downregulated in sham samples and the remote, non-infarcted LV but was upregulated in the infarct-only group, which were further enriched in the cell sheet treated group, thus suggestive of the enhancement of native ECM remodeling processes (Fig. 6F). For the vasculature development pathway, $\operatorname{Ndnf}(11)$ and $\operatorname{Adam12}$ (12), associated with angiogenic processes, were upregulated in the cell sheet-treated group (Fig. 6G).

Other upregulated genes were Notch3, a mediator of angiogenesis and vascular mural cell investment [13], and $C x c / 12$, a critical signaling molecule in the recruitment of endothelial progenitor cells $[14,15]$ in other preclinical models of post-MI remodeling, particularly in the border region (Fig. 6G). Collectively, these pathways establish transcriptome-wide changes in the left ventricular response to acute ischemia, indicating that the bi-level cell sheets gradually promote productive remodeling and prevent pathological ventricular dilation via these pathways and genes.

\section{SMC-EPC bi-level cell sheet induced morphologic reverse remodeling}

Eight weeks after MI, the left ventricular myocardial structure was superiorly maintained after SMC-EPC bi-level cell sheet transplantation compared with that in the untreated control, as assessed by hematoxylin-eosin staining (Fig. 7A). The SMC-EPC bi-level cell sheet attenuated cellular hypertrophy, as indicated by cellular diameter (cell sheet vs. untreated vs. sham, $16 \pm 2 \mu \mathrm{m}$ vs. $17 \pm 2 \mu \mathrm{m}$ vs. $14 \pm 2 \mu \mathrm{m}$, respectively) (Fig. 7B). 


\section{SMC-EPC bi-level cell sheet enhanced intramyocardial arterial density}

Eight weeks after Ml, well-structured vessel density (vWF/a-SMA-positive blood vessels) in the border zone myocardium increased in cell-sheet-treated animals compared to that in controls (cell-sheet vs. untreated, $4.8 \pm 1.4 / \mathrm{m}^{2}$ vs. $3.2 \pm 1.1 / \mathrm{m}^{2}$, respectively) (Fig. $7 \mathrm{C}$ ), suggesting enhanced angiogenesis in the cell sheet group.

\section{Engraftment of transplanted iron-labeled EPCs and SMCs in host myocardium}

To confirm the fate of transplanted iron-labeled EPCs and SMCs, Prussian blue staining was performed. Eight weeks after MI, iron-positive cells were detected in the attached cell sheet as well as in the host myocardium (Fig. 7D), suggesting engraftment and migration of transplanted iron-labeled EPCs and SMCs to the host myocardium.

\section{Angiogenesis into host myocardium from bi-level SMC-EPC cell sheet}

The created bi-level cell sheet maintained CD31-positive EPCs and SM22-a-positive SMCs in separate layers in vitro (Fig. 3C). The differentiation capacity of the transplanted human-derived EPCs and SMCs was assessed using immunoconfocal microscopy. As expected, immediately after cell sheet transplantation, immunoconfocal microscopy demonstrated an HLA-positive cell sheet construct attached to the epicardial membrane of the host myocardium (Fig. 7E). One week after cell sheet transplantation, CD31, a-SMA-positive, and Notch3-positive cells were detected in immunoconfocal microscopy of the host myocardium, whereas CD31- and a-SMA-positive, but Notch3-negative cells were found adjacent to the host myocardium (Fig. 7F). Importantly, Notch3, CD31, and a-SMA-positive blood vessel was observed in the border zone myocardium 1 week after cell sheet transplantation (Fig. 7G). Eight weeks after cell-sheet transplantation, according to the fate tracking of transplanted human-derived EPCs, HLA and vascular endothelial growth factor receptor 2 (VEGFR2) double-positive cells were detected in the host myocardium, suggesting that the transplanted EPCs in the border zone area were able to contribute directly to neovascularization of the host myocardium (Fig. $7 \mathrm{H}$ ). In addition, fate tracking of transplanted human male-derived SMCs was performed to identify male SMCs in female recipients of the SRY box transcription factor 1 (SOX1) gene in male cells. Immunostaining with antibodies for SOX1 and a-SMA demonstrated that SOX1-positive SMCs originating from the transplanted bi-level cell sheet migrated into the treated myocardial tissues and were able to contribute partly to the neovascularization of the host myocardium (Fig. 7I). These results indicate that transplanted EPCs and SMCs also directly contribute to the formation of new vessels in the host rodent myocardium.

\section{Discussion}


The development of novel therapies that are clinically translatable is critical if one hopes to transition research from the bench to the bedside. Although our prior SMC-EPC cell sheets were potent angiogenic constructs, using the rodent model as a cell source for EPC and SMC isolation precluded translation as a realistic therapy. Our study showed that the use of human-derived EPCs and SMCs in human subjects is promising.

We introduced human-derived EPCs isolated from peripheral blood and the SMC lineage when MSCs were cultured with SMC growth medium on ECM-coated dishes. A confluent bi-level cell sheet made of humanderived EPCs and SMCs was engineered using cell sheet technology. These advantages are most probably multifactorial in nature, by which the targeted transplantation of an SMC-EPC bi-level cell sheet induced the generation of structurally mature blood vessels and increased myocardial viability in the ischemic border zone myocardium, enhanced myocardial functional recovery, and limited adverse ventricular and myocardial remodeling in the athymic rodent model of MI. The observed increase in structurally mature vessel density in the ischemic border zone myocardium elucidated the significant in vivo angiogenic potential of this technology. A significantly enhanced vasculogenic potential was observed in vitro, wherein EPCs were stimulated with SMC-conditioned culture medium, indicating biological cross-talk by co-culturing SMCs and EPCs; this effect is a mechanistic component of the augmented angiogenesis demonstrated in vivo. More importantly, the data established direct migration of the transplanted EPCs and SMCs into the host myocardium and confirmed that these cells were some elements of a newly formed vasculature using our unique cell fate tracking experiments featuring xenogeneic transplantation. Moreover, the therapeutic potential of cell sheets was reflected by the upregulation of CXCL12, Notch3, Ndnf, Adam12, and Type VI collagen in the ischemic border zone myocardium, as indicated by bulk RNA Seq. Furthermore, regarding cell engraftment, the cell-sheettransplanted rat showed prolonged cell retention, as quantitatively assessed using USPIO-enhanced MRI. Thus, the robust angiogenic effect of bi-level cell sheets was because of the upregulation of angiogenesis-related genes; the recruitment of transplanted EPCs and SMCs improved myocardial viability, enhanced myocardial functional recovery, and induced reverse myocardial and ventricular remodeling of the ischemic heart.

Tissue engineering is a necessary tool for developing effective regenerative therapies [16]. In the past decade, using tissue engineering techniques, various cell scaffold therapies have been studied and are commercially available currently. One widely used therapy includes scaffold-based tissue engineering, which includes the use of biodegradable scaffolds [17], decellularized tissues [18], hydrogel and cell mixtures [19], bioprinting ]20], 3D bio-fabrication [21], and fiber-based tissue engineering [22]. Of these, our group employed the scaffold-free technology for cell-sheet engineering [23, 24].

A specialized dish that is covalently grafted with poly ( $\mathrm{N}$-isopropyl acrylamide) is used to create a cell sheet; poly ( $\mathrm{N}$-isopropyl acrylamide) is a temperature-responsive polymer which undergoes an enzymefree hydrophobic to hydrophilic transformation by temperature lowering [25]. Thus, using these dishes, three-dimensional tissues can be created from densely adherent cells, and an artificial scaffold or enzymatic digestion is not required. Cell sheets can be engineered easily and have an advantage of 
integrating within native tissue. These cell sheets preserve the cell-cell junctions and the extracellular matrix (ECM) deposited on the basal surface of the cell sheet in addition to regional morphological differences between different cell types following mobilization from the UpCell dish. SEM images showed spherical cells of the SMC layer, and a thin, film-like EPC mono-layer, consistent with the results reported previously [7].

Previously, using a rodent model of ischemic cardiomyopathy, we demonstrated that tissue-engineered cell sheets with rodent-derived SMCs and EPCs have advantages of the natural interactions between EPCs and SMCs, a structurally organized microvasculature, and functional recovery of distressed myocardium [6]. However, we observed the presence of SMCs in the thoracic aorta; it was also observed that bone marrow-derived MSCs have the potential to differentiate into various cell types, including SMCs. Considering the ECM regulates SMC phenotypic modulation, fibronectin was observed to guide the differentiation of MSCs into SMCs and simultaneously preserve cellular proliferative capacity [7]. Then, we indicated that the rodent origin bone marrow-derived, anatomically oriented bi-level cell sheet made of isolated EPCs and trans-differentiated SMCs is a multi-lineage cellular therapy, obtained from a translationally practical source. The following properties of tissue-engineered constructs make it an appropriate engineering combination for therapeutic use: maintenance of important interactions between EPCs and SMCs, thereby enhancing mature neovascularization within the border zone myocardium, minimization of post-infarction adverse remodeling, and strengthening of ventricular function in a rodent model of ischemic cardiomyopathy [5].

The mechanism by which SMC-EPC bi-level cell sheets induced blood vessel formation is dynamic and complex. Based on increased arterial density as shown by microscopy and preserved myocardial viability as shown by MEMRI in the ischemic border zone myocardium, the bi-level cell sheet containing humanderived EPCs and SMCs in separate layers was directly incorporated into the well-structured vasculature and remained present 8 weeks post-infarction in the cell fate tracking experiments.

This finding is consistent with our previous study [6]. Additionally, in this study, we elucidated an alternative exogenous mechanism underlying the therapeutic effect of SMC-EPC bi-level cell sheets in the acute MI rat model. The effect is observed because of the increased expression of CXCL12, Notch3, Ndnf, Adam12, and type VI collagen, as indicated by bulk RNA Seq.

Notably, CXCL12, also known as stromal cell-derived factor 1 (SDF-1), binds selectively to two chemokine receptors, namely CXCR4 and ACKR3 [26, 27]. CXCL12 increases vasculogenesis, limits infarct size, and improves cardiac function post-MI, as we reported previously $[28,29]$. Our group also reported that the CXCL12-dependent process facilitates the formation of collateral artery network and functional recovery of the heart [30], which supports our observations of the upregulated expression of CXCL12 and the wellstructured blood vessels in the ischemic border zone myocardium after SMC-EPC bi-level cell sheet transplantation. On the other hand, stem cell migration, recruitment, and homing are regulated by the interactions among cytokines, chemokines, and extracellular matrix, and the CXCL12/CXCR4 axis plays a central role in the mobilization of stem cells and their homing to ischemic tissues $[14,15]$. Thus, our 
findings are evidence of the direct contribution of donor's SMCs and EPC to the neovascularization in the recipient's ischemic myocardium.

Notch signaling is implicated in arteriogenesis [31] and intersects with hypoxic signaling, such as HIF1a [32]. Our data showed that Notch3 expression was upregulated under hypoxic conditions after ischemic injury, which is explained by the aforementioned report, whereas our key finding was that Notch3 expression was further upregulated in response to cell sheet transplantation, which was verified microscopically by a traditional immunohistochemical assessment. More interestingly, we observed the presence of Notch3/a-SMA/CD31-positive blood vessel formation in the ischemic border zone myocardium 1 week after SMC-EPC bi-level cell sheet transplantation. Notch3 regulates the involvement and stability of mural cells and pericytes and affects the vascular tone in resistance arteries as structurally supporting smooth muscle cells [33,34]. Based on these reports and our findings, possibilities include that the Notch3 signaling pathway was initiated as a maladaptive response to hypoxia post-MI and that Notch3 expression was effectively upregulated after cell sheet transplantation, indicating that Notch3 not only promotes blood vessel formation but is also implicated in the functional blood vessel by establishing vessel networks, assembling pericytes, and inducing the maturation of smooth muscle cells [35].

Elucidating the whole mechanism by which the SMC-EPC bi-level cell sheets limited adverse cardiac remodeling is difficult. The present study identified the reverse ventricular remodeling process, such as LV volume and LV mass, as measured using cardiac MRI images following cell sheet transplantation. In addition, cell sheet transplantation attenuated cellular hypertrophy in the non-infarcted remote myocardium, as observed microscopically. Based on these results of ventricular reverse remodeling as well as myocardial reverse remodeling, we attempted to explain the correlation between the two. First, neovascularization and the following improved myocardial viability on the targeted myocardial territory could reduce the number of necrotic/apoptotic cardiomyocytes. Next, the reduced accumulation of fibrous components would inhibit the thinning of the left ventricular wall $[36,37]$. Furthermore, the preserved wall thickness could reduce wall stress of the left ventricle, theoretically leading to reduced LV volume, known as adverse cardiac remodeling [38]. On the other hand, our data, together with the theory of Grossman et al. on volume-related cellular hypertrophy (i.e., cell thickening and elongation) [39], suggest that abolishing volume overload could activate cellular and extracellular mechanisms that modify myocardial structural remodeling. Moreover, as indicated by our bulk RNA sequencing, the native ECM remodeling processes were enhanced after cell sheet transplantation. Thus, we speculated that the release from volume overload could initiate a subsequent adjustable response in the molecular signals that result in the regression of myocardial hypertrophy and extracellular matrix turnover [40].

Cell engraftment is another critical aspect of myocardial regeneration. The present study focused on serial changes in a detailed fashion using a USPIO-enhanced MRI study on cell engraftment following cell-sheet transplantation. With regard to cell engraftment, the data demonstrated prolonged cell retention of the transplanted SMC-EPC cell sheets on the myocardium. The potential advantages of cell-sheet technology have been reported to include the delivery of a larger number of transplanted cells and the 
integration with native tissues without destroying the cell-cell or cell-ECM adhesions in the cell sheet [41, 42]. The degree of neovascularization in the transplanted myocardium and subsequent myocardial inflammation after cell sheet transplantation affect the retention and engraftment of transplanted cells in cell sheet therapy $[43,44]$. Based on these findings and the significant findings of long-standing cell retention and the recruitment of transplanted cells from the SMC-EPC bi-level cell sheet, the SMC-EPC cell sheet might have improved the hypoxic environment in the transplanted area to a greater degree, thus potentially improving initial and long-term cell engraftment through a higher expression of associated genes [45].

Finally, type $\mathrm{VI}$ collagen not only aids cell attachment and connects with the surrounding matrix but also acts as an early sensor of the injury/repair response [46,47], whereas type VI collagen contributes to angiogenesis [48]. Thus, the potential mechanism is that the upregulated expression of type VI collagen in the ischemic border zone area may directly initiate neovascularization in the corresponding myocardium and contribute to maintaining cell engraftment after cell sheet transplantation.

Currently, this therapy for acute $\mathrm{Ml}$ is not appropriate for use in clinical settings because of the time required for the isolation, cultivation, and manipulation of the cells in vitro. Despite this, this construct is a potential candidate for allogeneic therapy. The utility of these cell sheets for the treatment of chronic ischemic cardiomyopathy and diabetic cardiomyopathy is currently being studied, including the examination of the survival duration of the transplanted cells. Finally, the efficiency of bilayer cell sheets in comparison with those of EPC, SMC, or MSC monolayer cell sheets requires further studies.

In conclusion, the human-derived, anatomically oriented bi-level cell sheets made of isolated EPCs and transdifferentiated SMCs are a promising, multi-lineage cellular therapy obtained from a translationally practical source. Delivery of a tissue-engineered construct that maintains important interactions between EPCs and SMCs enhances structurally mature neovascularization within the border zone myocardium along with myocardial upregulation of the expression of angiogenesis-related genes as well as direct migration of transplanted EPCs and SMCs, increases myocardial viability, minimizes post-infarction adverse remodeling, and strengthens ventricular function. Collectively, these pathways establish transcriptome-wide changes in the left ventricular response to acute ischemia, indicating that the bi-level cell sheets gradually promote productive remodeling and prevent pathological ventricular dilation via these pathways and genes.

\section{Declarations}

Data availability: All data generated or analyzed during this study are included in this published article and the datasets generated during and/or analyzed during the current study are available from the corresponding author on reasonable request.

\section{Acknowledgements}


This work was supported by Stanford Cardiovascular Institute (CVI) and Gootter Foundation Seed Grant Awards (Y.S.), NIH R01 HL089315-7 (Y.J.W.), NIH R01 HL133272 (J.C.W.), and NIH R01 HL145676 (J.C.W.).

Author contributions: Conceptualization, H.S.S., A.T., I.Y.C., Y.J.W., Y.S.; methodology, H.S.S., A.T., Y.T., G.I., I.Y.C., Y.S.; formal analysis, H.S.S., A.T., Y.T., G.I., I.Y.C., D.C., A.J.P.; investigation, H.S.S., A.T., Y.T., G.I., I.Y.C., D.C., K.J.J., A.J.P., M.K., Y.S.; resources, H.S.S., A.T., Y.J.W., Y.S.; data curation, H.S.S., A.T., Y.T., D.C., Y.J.W., Y.S.; writing-original draft preparation, H.S.S., A.T., Y.T., D.C., Y.S.; writing-review and editing, H.S.S., Y.T., A.J.P., P.C.Y., J.C.W., Y.J.W., Y.S.; visualization, H.S.S., A.T., Y.T., I.Y.C., D.C., A.J.P., P.C.Y., Y.J.W.; supervision, Y.J.W., Y.S.; project administration, H.S.S., A.T., Y.S.; funding acquisition, J.C.W., Y.J.W., Y.S. All authors have read and agreed to the published version of the manuscript.

\section{Competing interests: None.}

\section{References}

1. Go AS, Mozaffarian D, Roger VL, Benjamin EJ, Berry JD, Borden WB, Bravata DM, Dai S, Ford ES, Fox CS, Franco S, Fullerton HJ, Gillespie C, Hailpern SM, Heit JA, Howard VJ, Huffman MD, Kissela BM, Kittner SJ, Lackland DT, Lichtman JH, Lisabeth LD, Magid D, Marcus GM, Marelli A, Matchar DB, McGuire DK, Mohler ER, Moy CS, Mussolino ME, Nichol G, Paynter NP, Schreiner PJ, Sorlie PD, Stein J, Turan TN, Virani SS, Wong ND, Woo D, Turner MB. Executive summary: Heart disease and stroke statistics-2013 update: A report from the american heart association. Circulation. 2013;127:143152.

2. O'Gara PT, Kushner FG, Ascheim DD, Casey DE, Jr., Chung MK, de Lemos JA, Ettinger SM, Fang JC, Fesmire FM, Franklin BA, Granger CB, Krumholz HM, Linderbaum JA, Morrow DA, Newby LK, Ornato JP, Ou N, Radford MJ, Tamis-Holland JE, Tommaso CL, Tracy CM, Woo YJ, Zhao DX. 2013 accf/aha guideline for the management of st-elevation myocardial infarction: Executive summary: A report of the american college of cardiology foundation/american heart association task force on practice guidelines. Journal of the American College of Cardiology. 2013;61:485-510.

3. Heidenreich PA, Trogdon JG, Khavjou OA, Butler J, Dracup K, Ezekowitz MD, Finkelstein EA, Hong Y, Johnston SC, Khera A, Lloyd-Jones DM, Nelson SA, Nichol G, Orenstein D, Wilson PW, Woo YJ. Forecasting the future of cardiovascular disease in the united states: A policy statement from the american heart association. Circulation. 2011;123:933-944.

4. Boodhwani M, Sodha NR, Laham RJ, Sellke FW. The future of therapeutic myocardial angiogenesis. Shock. 2006;26:332-341.

5. Shudo Y, Goldstone AB, Cohen JE, Patel JB, Hopkins MS, Steele AN, Edwards BB, Kawamura M, Miyagawa S, Sawa Y, Woo YJ. Layered smooth muscle cell-endothelial progenitor cell sheets derived from the bone marrow augment postinfarction ventricular function. J Thorac Cardiovasc Surg 2017;154(3):955-963. 
6. Shudo Y, Cohen JE, MacArthur JW, Atluri P, Hsiao PF, Yang EC, et al. Spatially oriented, temporally sequential smooth muscle cell-endothelial progenitor cell bi-level cell sheet neovascularizes ischemic myocardium. Circulation 2013;128 (11 Suppl 1): S59-S68.

7. Shudo Y, Cohen JE, Goldstone AB, MacArthur JW, Patel J, Edwards BB, et al. Transdifferentiation of Mesenchymal Stem Cell into Smooth Muscle Cell Lineage; Utility for Clinical Application From Isolation to Creation of Cell-Sheet. Cytotherapy 2016;18:510-517.

8. Subramanian A, Tamayo P, Mootha VK, Mukherjee S, Ebert BL, Gillette MA, Paulovich A, Pomeroy SL, Golub TR, Lander ES, Mesirov JP. Gene set enrichment analysis: a knowledge-based approach for interpreting genome-wide expression profiles. Proc Natl Acad Sci USA 2005;102(43):15545-15550.

9. Mootha VK, Lindgren CM, Eriksson K, Subramanian A, Sihag S, Lehar J, et al. PGC-1 alpha-responsive genes involved in oxidative phosphorylation are coordinately downregulated in human diabetes. Nat Genet 2003;34(3):267-273.

10. Marro J, Pfefferli C, Charles ADP, Bise T, Jazwinska A. Collagen XII Contributes to Epicardial and Connective Tissues in the Zebrafish Heart during Ontogenesis and Regeneration. Plos One 2016;11(10):e0165497.

11. Ohashi K, Enomoto T, Joki Y, Shibata R, Ogura Y, Kataoka Y, et al. Neuron-derived neurotrophic factor functions as a novel modulator that enhances endothelial cell function and revascularization processes. J Bio Chem 2014;289(20):14132-14144.

12. Dokun AO, Chen L, Okutsu M, Farber CR, Hazarika S, Jones WS, et al. ADAM12: a genetic modifier of preclinical peripheral arterial disease. Am J Physiol Heart Circ Physiol 2015;309(5):H790-H803.

13. Liu H, Zhang W, Kennard S, Caldwell RB, Lilly B. Notch3 is critical for proper angiogenesis and mural cell investment. Circ Res 2010;107(7):860-870.

14. Imanishi Y, Miyagawa S, Fukushima S, Ishimaru K, Sougawa N, Saito A, et al. Sustained-release delivery of prostacyclin analogue enhances bone marrow-cell recruitment and yields functional benefits for acute myocardial infarction in mice. PloS One 2013 Jul 19;8(7):e69302.

15. Ceradini DJ, Kulkarni AR, Callaghan MJ, Tepper OM, Bastidas N, et al. Progenitor cell trafficking is regulated by hypoxic gradients through HIF-1 induction of SDF-1. Nat Med 2004 Aug;10(8):858-864.

16. Langer R, Vacanti JP. Tissue engineering. Science 1993;260:920-926.

17. Atluri P, Trubelja A, Fairman AS, Hsiao P, MacArthur JW, Cohen JE, et al. Normalization of postinfarct biomechanics using a novel tissue-engineered angiogenic construct. Circulation 2013;128(11 Suppl 1):S95-S104.

18. Neumann A, Sarikouch S, Breymann T, Cebotari S, Boethig D, Horke A, et al. Early systemic cellular immune response in chindren and young adults receiving decellularized fresh allografts for pulmonary valve replacement. Tissue Eng Part A. 2014;20:1003-1011.

19. Cohen JE, Purcell BP, MacArthur JW Jr, Mu A, Shudo Y, Patel JB, et al. A bioengineered hydrogel system enables targeted and sustained intramyocardial delivery of neuregulin, activating the cardiomyocyte cell cycle and enhancing ventricular function in a murine model of ischemic cardiomyopathy. Circ Heart Fail. 2014;7:619-626. 
20. Murphy SV, Atala A. 3D bioprinting of tissues and organs. Nat Biotechnol 2014;32:773-785.

21. Shudo Y, MacArthur JW, Kunitomi Y, Joubert L, Kawamura M, Ono J, et al. Three-dimensional multilayered microstructure using needle array bioprinting system. Tissue Eng Part A 2020;26(56):350-357.

22. Onoe H, Okitsu T, Itoh A, Kato-Negishi M, Gojo R, Kiriya D, et al. Metre-long cell-laden microfibers exhibit tissue morphologies and functions. Nat Mater 2013;12:584-590.

23. Sawa Y, Miyagawa S, Sakaguchi T, Fujita T, Matsuyama A, Saito A, et al. Tissue engineered myoblast sheets improved cardiac function sufficiently to discontinue LVAS in a patient with DCM: report of a case. Surg Today. 2012;42:181-184.

24. Yamamoto R, Miyagawa S, Toda K, Kainuma S, Yoshioka D, Yoshikawa Y, et al. Long-term outcome of ischemic cardiomyopathy after autologous myoblast cell-sheet implantation. Ann Thorac Surg 2019;108(5):e303-e306.

25. Okano T, Yamada N, Sakai H, Sakurai Y. A novel recovery system for cultured cells using plasmatreated polystyrene dishes grafted with poly (N-iso-propylacrylamide). J Biomed Mater Res 1993;27:1243-1251.

26. Bleul CC, Fuhlbrigge RC, Casasnovas JM, Aiuti A, Springer TA. A highly efficacious lymphocyte chemoattractant, stromal cell-derived factor (SDF-1). J Exp Med 1996 Sep 1;184(3):1101-1109.

27. Oberlin E, Amara A, Bachelerie F, Bessia C, Virelizier JL, Arenzana-Seisdedos F, et al. The CXC chemokine, stromal cell derived factor 1 (SDF-1), is the ligand for LESTR/fusin and prevents infection by lymphocyte-tropic HIV-1 syncytium-inducing strains. Nature 1996 Aug 29;382(6594):833-835.

28. Hiesinger W, Perez-Aguilar JM, Atluri P, Marotta NA, Frederick JR, Fitzpatrick JR 3rd, McCormick RC, Muenzer JR, Yang EC, Levit RD, Yuan LJ, Macarthur JW, Saven JG, Woo YJ. Stromal cell-derived factor-1alpha activation of tissue-engineered endothelial progenitor cell matrix enhances ventricular function after myocardial infarction by inducing neovasculognesis. Circulation 2011 Sep 13;124(11 Suppl):S18-26.

29. MacArthur JW Jr, Purcell BP, Shudo Y, Cohen JE, Fairman A, Trubelja A, Patel J, Hsiao P, Yang E, Lloyd K, Hiesinger W, Atluri P, Burdick JA, Woo YJ. Sustained release of engineered stromal cell-derived factor 1-a from injectable hydrogels effectively recruits endothelial progenitor cells and preserves ventricular function after myocardial infarction. Circulation 2013 Sep 10;128(11 Suppl 1):S79-86.

30. Das S, Goldstone AB, Wang H, Farry J, D'Amato G, Paulsen M, et al. A unique collateral artery development program promotes neonatal heart regeneration. Cell;176(5):1128-1142.e18.

31. Heil M, Eitenmuller I, Schmitz-Rixen T, Schaper W. Arteriogenesis versus angiogenesis: similarities and differences. J Cell Mol Med 2006;10(1):45-55.

32. Poellinger $L$, Lendahl U. Modulating notch signaling by pathway-intrinsic and pathway-extrinsic mechanisms. Curr Opin Genet Dev 2008;18(5):449-454.

33. de Chantemele EJB, Retailleau K, Vessierres E, Bocquet A, Guihot AL, Lemaire B, Domenga V, Baufreton $\mathrm{C}$, et al. Notch3 is a major regulator of vascular tone in cerebral and tail resistance arteries. 
Arterioscler Thromb Vasc Biol 2008;28(12):2216-2224.

34. Domenga V, Fardoux P, Lacombe P, Monet M, Maciazek J, Krebs LT, et al. Notch3 is required for arterial identity and maturation of vascular smooth muscle cells. Genes Dev 2004;18(22):27302735.

35. Liu H, Zhang W, Kennard S, Caldwell RB, Lilly B. Notch3 is critical for proper angiogenesis and mural cell investment. Circ Res 2010;107(7):860-870.

36. Carmeliet $P$, Jain RK. Molecular mechanisms and clinical applications of angiogenesis. Nature 2011;473(7347):298-307.

37. Growing P, Conway EM. Growing better blood vessels. Nat Biotechnol 2001;19:1019-1020.

38. Shudo Y, Taniguchi K, Takeda K, Sakaguchi T, Funatsu T, Matsue H, Miyagawa S, Kondoh H, Kainuma S, Kubo K, Hamada S, Izutani H, Sawa Y. Restrictive mitral annuloplasty with or without surgical ventricular restoration in ischemic dilated cardiomyopathy with severe mitral regurgitation. Circulation 2011 Sep 13;124(11 Suppl):S107-14.

39. Grossman W, Jones D, McLaurin L. Wall stress and patterns of hypertrophy in the human left ventricle. J Clin Invest. 1975;56:56-64.

40. Beeri R, Yosefy C, Guerrero JL, Nesta F, Abedat S, Chaput M, et al. Mitral regurgitation augments postmyocardial infarction remodeling failure of hypertrophic compensation. J Am Coll Cardiol. 2008;51:476-86.

41. Shudo Y, Miyagawa S, Fukushima S, Kainuma S, Saito A, Toda K, et al. Promising Therapeutic Effects of Cell Sheet Implantation with a Pedicle Omentum Flap to Enhance the Angiogenic Response to Ischemic Cardiomyopathy. J Stem Cell Res Ther 2014;4:1.

42. Shudo Y, Miyagawa S, Fukushima S, Saito A, Shimizu T, Okano T, et al. Novel regenerative therapy using cell-sheet covered with omentum flap delivers a huge number of cells in a porcine myocardial infarction model. J Thorac Cardiovasc Surg 2011;142:1188-1196.

43. Narita T, Shintani Y, Ikebe C, Kaneko M, Harada N, Tshuma N, et al. The use of cell-sheet technique eliminates arrhythmogenicity of skeletal myoblast-based therapy to the heart with enhanced therapeutic effects. Int J Cardiol 2013 Sep 20;168(1):261-269.

44. Shimizu T, Sekine H, Yang J, Isoi Y, Yamato M, Kikuchi A, et al. Polysurgery of cell sheet grafts overcomes diffusion limits to produce thick, vascularized myocardial tissues. FASEB J 2006;20(6):708-710.

45. Kainuma S, Miyagawa S, Fukushima S, Pearson J, Chen YC, Saito A, et al. Cell-sheet therapy with omentopexy promotes arteriogenesis and improves coronary circulation physiology in failing heart. Mol Ther 2015;23(2):374-386.

46. Keene DR, Engvall E, Glanville RW. Ultrastructure of type VI collagen in human skin and cartilage suggests an anchoring function for this filamentous network. J Cell Biol 1988;107:1996-2006.

47. Bonaldo P, Russo V, Bucciotti F, Doliana R, Colombatti A. Structural and functional features of the alpha 3 chain indicate a bridging role for chicken collagen $\mathrm{VI}$ in connective tissues. Biochemistry 1990;29:1245-1254. 
48. Chen P, Cescon M, Bonaldo P. Collagen VI in cancer and its biological mechanisms. Trends Mol Med 2013;19:410-417.

49. Masouleh BK, Baraniskin A, Schmiegel W, Schroers R. Quantification of circulating endothelial progenitor cells in human peripheral blood: establishing reliable flow cytometry protocol. J Immunol Methods. 2010;357(1-2):38-42.

50. Shudo Y, Miyagawa S, Ohkura H, Fukushima S, Saito A, Shiozaki M, et al. Addition of mesenchymal stem cells enhances the therapeutic effects of skeletal myoblast cell-sheet transplantation in a rat ischemic cardiomyopathy model. Tissue Engineering Part A 2013;20:728-739.

51. Kawamura M, Paulsen MJ, Goldstone AB, Shudo Y, Wang H, Steele AN, et al. Tissue-engineered smooth muscle cell and endothelial progenitor cell bi-level cell sheets prevent progression of cardiac dysfunction, microvascular dysfunction, and interstitial fibrosis in a rodent model of type 1 diabetesinduced cardiomyopathy. Cardiovasc Diabetol. 2017 Nov 2;16(1):142.

52. Dash R, Kim PJ, Matsuura Y, Ikeno F, Metzler S, Huang NF, et al. Manganese-Enhanced Magnetic Resonance Imaging Enables In Vivo Confirmation of Peri-Infarct Restoration Following Stem Cell Therapy in a Porcine Ischemia-Reperfusion Model. J Am Heart Assoc 2015 Jul 27;4(7):e002044.

53. Dash R, Chung J, Ikeno F, Hahn-Windgassen A, Matsuura Y, Bennett MV, et al. Dual ManganeseEnhanced and Delayed Gadolinium-Enhanced MRI Detects Myocardial Border Zone Injury in a Pig Ischemia-Reperfusion Model. Circ Cardiovasc Imaging 2011 Sep;4(5):574-82.

54. Thu MS, Bryant LH, Coppola T, Jordan EK, Budde MD, Lewis BK, et a. Self-assembling nanocomplexes by combining ferumoxytol, heparin and protamine for cell tracking by magnetic resonance imaging. Nat Med 2012;18 (3):463-467.

55. Castaneda RT, Khurana A, Khan R, Daldrup-Link HE. Labeling stem cells with ferumoxytol an FDAapproved iron oxide nanoparticle. J. Vis. Exp. 2011;57:e3482.

\section{Figures}

\section{Figure 1}

Characterization of endothelial progenitor cells (EPCs), smooth muscle cells (SMCs), and SMC-EPC bilevel cell sheets. (A) SMC-EPC bi-level cell sheet manufacturing protocol. (B) Immunocytochemistry demonstrated CD31 (red) and CD34 (green) on EPCs. The cell nuclei were counterstained with 4',6diamidino-2-phenylindole (DAPI, blue). Scale bar $=50 \mu \mathrm{m}$. (C) Representative flow cytometry histogram of cultured EPCs. Red indicates unstained cells as negative control; blue, EPCs. (D) Immunocytochemistry demonstrated smooth muscle protein 22-alpha (SM22-a, red) and caldesmon (green) on SMCs. The cell nuclei were counterstained with DAPI (blue). Scale bar $=50 \mu \mathrm{m}$. (E) Representative flow cytometry histogram of cultured SMCs. Red indicates unstained cell as negative control; blue, transdifferentiated 
SMCs; green, primary human-derived SMCs as a positive control. MSC, mesenchymal stem cell; a-SMA, alpha-smooth muscle actin.

A
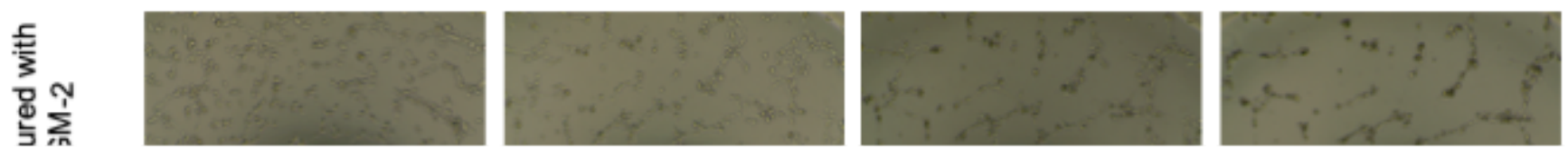

\section{Figure 2}

In-vitro quantification of vasculogenesis by Matrigel angiogenesis assay. Representative images demonstrating enhanced angiogenesis of endothelial progenitor cells (EPCs) in the presence of the conditioned endothelial cell growth medium (EGM)-2 mediated by SMC compared with that in the 
presence of fresh EGM-2 control. A statistically significant increase in vessel number, length, and branches was evident in the conditioned EGM-2 medium group compared with that in the fresh EGM-2 medium control ( $\mathrm{n}=8$ in each).

A $37^{\circ} \mathrm{C}$

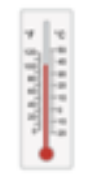

${ }^{22^{\circ} \mathrm{C}}$

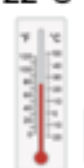

D

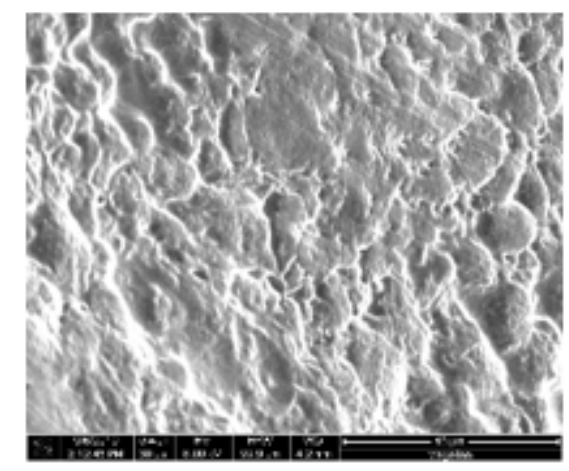

B

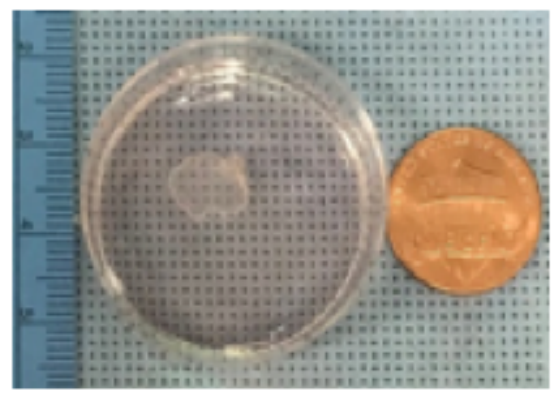

$\mathrm{E}$

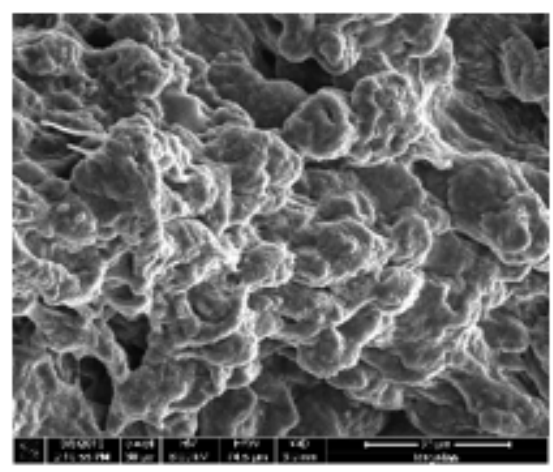

C

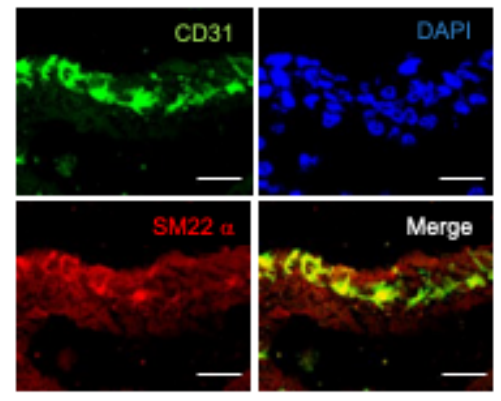

$\mathrm{F}$

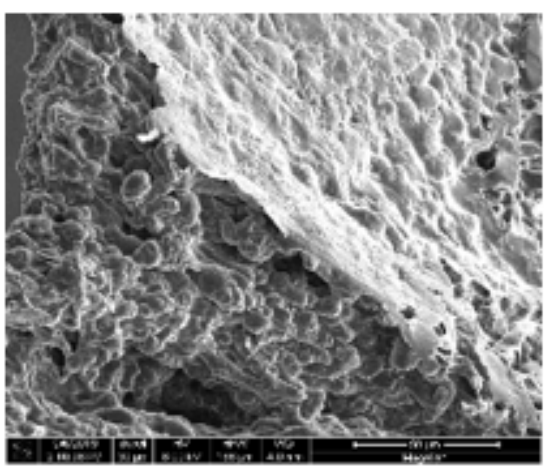

Figure 3

Creation and characterization of the smooth muscle cell (SMC)-endothelial progenitor cell (EPC) bi-level cell sheet. (A) The diagram shows the methods for engineering the cell sheet. Cell-sheet is harvested from the temperature-responsive culture dish. (B) A round-shaped scaffold-free SMC-EPC bi-level cell sheet in a 35-mm dish. (C) The bi-level cell sheet maintained CD31 positive EPC and SM22-a positive SMC in separate layers. Green indicates CD31; red, SM22-a. The cellular nuclei were counterstained with 4',6diamidino-2-phenylindole (DAPI, blue). Scale bar $=50 \mu \mathrm{m}$. (D-F) Representative scanning electron microscope (SEM) images of SMC-EPC bi-level cell sheet. (d) The examination of the surface (EPC layer) of the SMC-EPC bi-level cell sheet suggested that EPCs form a smooth confluent layer with cell borders in close contact with each other, thereby forming a thin film-like layer on top of the SMC. (E) The examination of the bottom (SMC layer) of the SMC-EPC bi-level cell sheet indicated that SMC morphology varies regionally from spherical to flattened, suggesting that SMCs differentiated into an elongated and spindle-shaped dense sheet-like construct with cellular extensions forming a densely adherent layer. (F) The interface between the two layers of the SMC-EPC bi-level cell sheet (SMC-EPC border-zone) showed the development of a cross-linked structure. 
A

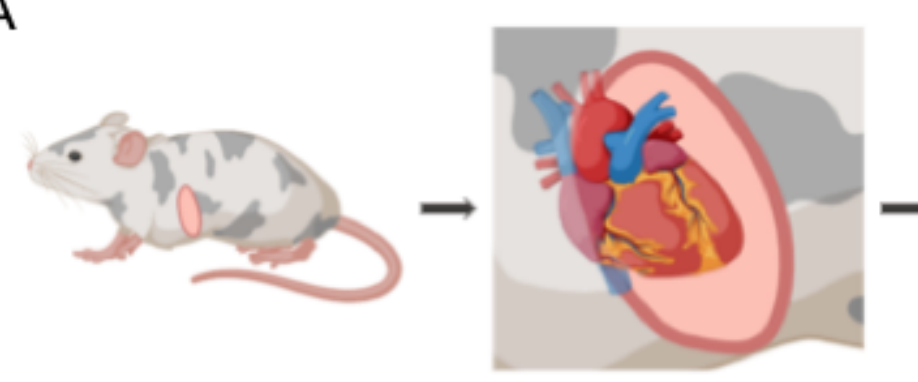

Sham

B
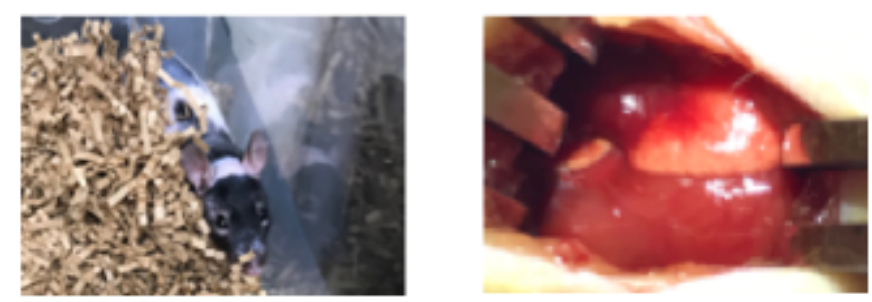

Sham

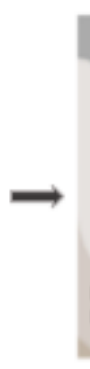

Untreated control

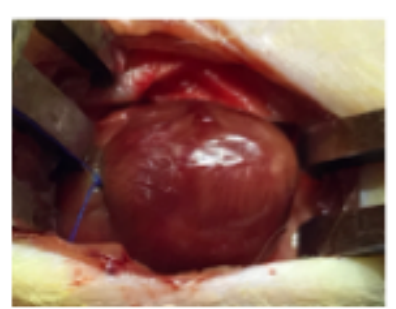

Untreated control

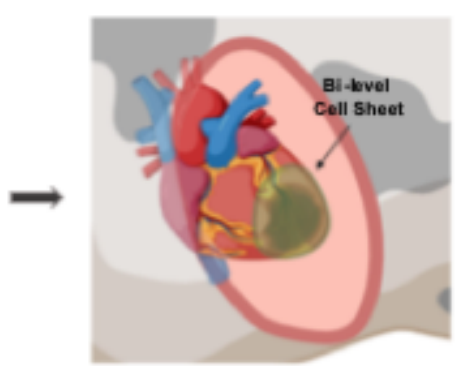

Cell sheet

\section{C}

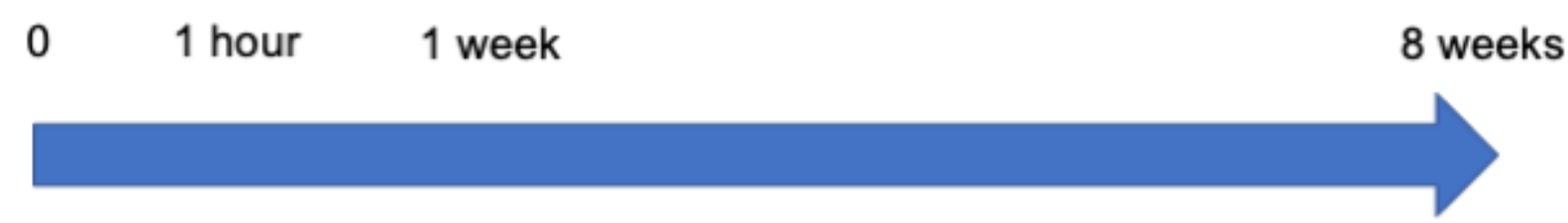

USPIO Enhanced MRI at 0, 7, 14, 21, 28, 42, 56 days

Histology

Cardiac MRI

MEMRI

Histology

\section{Figure 4}

Experimental technique and protocol timeline. (A) A schema illustrating induction of myocardial infarction (MI) by ligating the left anterior descending coronary artery permanently and smooth muscle cell (SMC)-endothelial progenitor cell (EPC) bi-level cell sheet transplantation technique via a left thoracotomy approach. (B) Pictures of the operated rats of three groups: transplantation of SMC-EPC bilevel cell sheet (cell sheet group), no treatment (untreated control group), or a sham operation (a positive 
control). (C) Timeline of the experimental protocol. USPIO, ultrasmall superparamagnetic iron oxide; MRI, magnetic resonance imaging; MEMRI, manganese-enhanced magnetic resonance imaging.

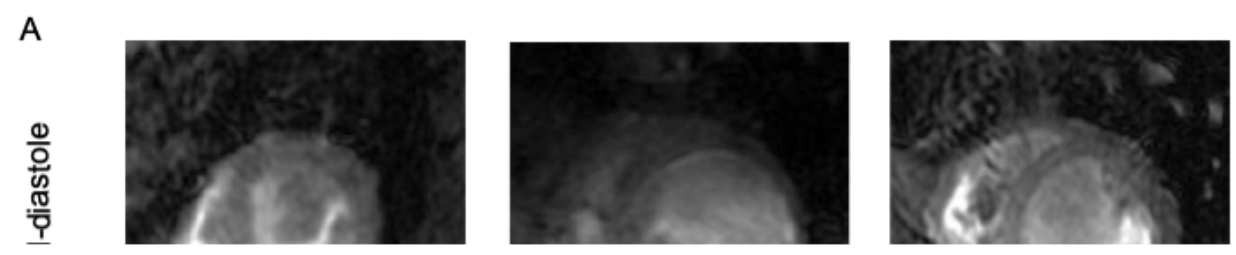

Figure 5 
Cardiac magnetic resonance image (MRI) and manganeseenhanced magnetic resonance image (MEMRI) to evaluate cardiac function, left ventricular (LV) dimension, LV mass, and myocardial viability.

(A) Representative cardiac MRI at end-diastolic and end-systolic phases for cell sheet-treated $(n=10)$, untreated control $(n=14)$, and sham control $(n=10)$ groups. Examinations were performed 8 weeks after myocardial infarction. (B) Representative MEMRI for cell sheet-treated $(n=10)$, untreated control $(n=14)$, and sham control $(n=10)$ groups. Examinations were performed 8 weeks after myocardial infarction.

Ultrasmall superparamagnetic iron oxide (USPIO)-enhanced MRI to assess cell engraftment of transplanted donor cells. (C) Representative hypointense lesions of iron-labeled cell sheet transplantation site at 0 (baseline), 7, 14, 21, 28, 42, and $56 \mathrm{~d}$ after treatment. Short-axis magnetic resonance imaging showing hypointense lesions (white arrow) caused by the transplanted cell sheet adjacent to the anterior

surface of the left ventricle. (D) Table of longitudinal change of cell engraftment ratio following cell-sheet transplantation. In the period of $7 \mathrm{~d}$ after cell-sheet transplantation, the cell engraftment ratio was maintained as high as $92.4 \%$ of baseline. Next, regression of cell engraftment was found, and then the ratio decreased to $72.5 \%$ of baseline at $14 \mathrm{~d}$ after the treatment. During the period of 14 to $42 \mathrm{~d}$, this ratio was maintained at approximately $70 \%$ of baseline. Cell engraftment ratio at $56 \mathrm{~d}$ was still as high as $56.3 \%$ of baseline.

Figure 6

Bulk RNA sequencing to comprehensively evaluate the effect of smooth muscle cell (SMC)-endothelial progenitor cell (EPC) bi-level cell sheet implantation on native tissue biological process following myocardial infarction. (A) Heart tissue was collected 7 days after surgery and we separated the left ventricle into three zones encompassing the infarct, infarct border zone, and unaffected (remote) tissue.

(B) Principal component analysis of the individual samples highlighted variable signatures in the anterior LV (infarct) and border zone regions between the cell sheet and untreated myocardial infarction models. (C) We identified 114 significantly enriched processes in cell sheet-treated hearts, including multiple pathways related to primitive morphogenesis, biological adhesion, and vasculature development. (D, E) Infarct samples showed significant enrichment for pathways related to mitochondrial energetics, oxidative phosphorylation, and protein translation. $(F)$ Within the adhesion pathway, we found heightened expression of critical ECM components following cell sheet treatment, including several collagen $\mathrm{VI}$ isoforms and multiple collagen subtypes associated with cardiac development and response to injury (Col12a1 and Col1a1). Each of these genes had low expression in sham samples and the remote, noninfarcted LV but showed enhanced expression following infarction, which was further enriched in cell sheet-treated samples, suggesting amplification of native ECM remodeling processes. (G) Within the vasculature development pathway, we observed heightened expression of Ndnf and Adam12, genes with known roles in angiogenic processes following cell sheet transplantation. 


\section{Figure 7}

Histological Assessment. (A) Representative images of hematoxylin-eosin stained myocardial sections along the short axis for untreated control, smooth muscle cell (SMC)-endothelial progenitor cell (EPC) bilevel cell sheet, and sham surgery control groups. (B) The representative periodic acid-Schiff stained myocardial section along the short axis in the remote non-infarct myocardium for untreated control, SMCEPC bi-level cell sheet, and sham surgery control groups. Scale bar $=50 \mu \mathrm{m}$. (C) Representative vWF and alpha-smooth muscle actin (a-SMA) staining of the border zone myocardium for untreated control, SMCEPC bi-level cell sheet, and sham surgery control groups. Red indicates von Willebrand factor (vWF); green, a-SMA; blue, nuclei. (D) Representative images of Prussian blue-stained myocardial sections along the short axis 8 weeks after iron-labeled SMC-EPC bi-level cell-sheet transplantation. Iron-positive cells were detected in the attached cell sheet (black arrow) and host myocardium (arrowhead). (E) Immediately after cell sheet transplantation, immunoconfocal microscopy demonstrated human leukocyte antigen (HLA)-positive cell sheet constructs attached to the epicardial membrane of the host myocardium. Green indicates HLA; blue, nuclei. Scale bar $=50 \mu \mathrm{m}$. (F) One week after cell sheet transplantation, immunoconfocal microscopy showed CD31, a-SMA-positive, and Notch3-positive cells in the host myocardium, whereas CD31 and a-SMA-positive, but Notch3-negative cell sheet construct was attached to the host myocardium. Green indicates Notch3; red, a-SMA; yellow, CD31; blue, nuclei. (G) Representative Notch3, CD31, and a-SMA staining of the border zone myocardium for the SMC-EPC bilevel cell sheet transplanted group. Green indicates Notch3; red, a-SMA; yellow, CD31; blue, nuclei. (H) Fate tracking of transplanted human-derived EPCs performed with anti-HLA and anti-vascular endothelial growth factor receptor 2 (VEGFR2). Immunostaining for HLA and VEGFR2 showed that transplanted EPCs over the border zone area contributed to myocardium neovascularization 8 weeks after transplantation. Green indicates HLA; red, VEGFR2; blue, nuclei. Scale bar $=50 \mu \mathrm{m}$. (I) Fate tracking of transplanted human male-derived SMCs performed with fluorescence in-situ hybridization to identify male SMCs in the female recipient for SRY box transcription factor 1 (SOX1) gene of male cells. Immunostaining with an antibody against SOX1 and a-SMA demonstrated that SOX1-positive SMCs originating from the transplanted bi-level cell sheet migrated into the treated myocardial tissues and contributed partly to myocardium neovascularization 8 weeks after transplantation. Green indicates SOX1; red, a-SMA; blue, nuclei. Scale bar $=200 \mu \mathrm{m}$. 